\title{
Fuzzy Logic based Anti-Slip Control of Commuter Train with FPGA Implementation
}

\author{
Fozia Hajano ${ }^{1}$, Farzana Rauf Abro $^{3}$ \\ Department of Electronic Engineering \\ Mehran University of Engineering and Technology \\ Jamshoro, Pakistan \\ Tayab D Memon ${ }^{2}$ \\ Department of Electronic Engineering \\ Mehran University of Engineering and Technology \\ National Center of Robotics and Automation \\ HHCMS, Jamshoro \\ Pakistan
}

\author{
Imtiaz Hussain Kalwar ${ }^{4}$ \\ Department of Electrical Engineering \\ DHA Suffa University \\ Karachi, Pakistan
}

\author{
Burhan $^{5}$ \\ Department of Electronic Engineering \\ Mehran University of Engineering and Technology \\ Jamshoro, Pakistan
}

\begin{abstract}
In the railway industry, slip control has always been essential due to the low friction and low adhesion between the wheels and the rail and has been an issue for the design, activity, and operation of railroad vehicles. Slip is an unpredictable parameter in the railroad that disintegrates the surface of the railroad with a contact surface of the boggy wheel brought about by the mechanical force of traction phenomena, it destabilizes the railway traction which does not fulfill safety and punctuality requirements. In this paper, we present the work based on developing a fuzzy logic-based anti-slip controller for the commuter train using FPGA implementation which minimizes slip parameters. The development of a fuzzy logicbased anti-slip controller for the commuter train is designed in MATLAB and then tested for area-performance parameters in FPGA through the system generator library. Simulation is performed to demonstrate the effectiveness of the proposed fuzzy logic control system for anti-slip control under various parameters, the results of simulation prove the effectiveness of the proposed control system as compared with conventional PID controller and shows high anti-slip control performance under nonlinearity of brake dynamics.
\end{abstract}

Keywords-Wheel rail contact condition; anti-slip; railway wheelset fuzzy logic; FPGA hardware estimation

\section{INTRODUCTION}

With the beginning of railroad travel, in movement and plan of the rail route vehicles, adhesive force has been a basic parameter among rail and wheel, especially when the leaves are beaten and develop a low-bond contaminant film on the rail surface amid pre-winter leaf falls, which is to an extraordinary degree difficult to remove. Adhesion, the force between the wheel and rail, influences the performance and safety of railroad vehicles. Wheel- rail adhesive force must be adequate for safety and punctuality requirements because low adhesive force during driving diminishes acceleration and this will expand the braking distance, which is a security issue, besides this if adhesive force is too high it produces shear stress and sever surface fatigue.
Wheel-rail contact is an open system, two main factors influence rail-road contact conditions such as Environmental conditions including weather (moisture, humidity, dry) and different contaminants (snow, dirt, oil, autumn leaves, unwanted grass and plants alongside railway track) every autumn thousands of tons of leaves fall on the tracks as they are compacted they form a smooth and slippery layers that stick to the tracks which cause trains to accelerate and brake gently. The hot climate can likewise influence the rails, the rail can bend, expand and can break in the heat, rain or flood water can harm equipment or wash away ballast (crushed stone and debilitate the track, Strong winds can blow branches, trees, and trash onto the train track and drawdown overhead power lines affecting adhesive force. Wheel-rail adhesive force may be too high or maybe too low and it is difficult to predict. The prediction of the wheel-rail adhesion is very important for railway operation and simulation of multi-body vehicle dynamics. Therefore, an anti-slip controller needs to be designed to control slipping or sliding and as a core of antislip, we have chosen fuzzy logic-based anti-slip control of commuter trains using FPGA.

The rest of the paper proceeds as follows. In section II, a literature survey is presented that is followed by the dynamic equations in section III and presented the wheelset model in section IV. In sections V and VI, PID and fuzzy logic based anti-slip control models are presented. In section VII, simulation results taken in MATLAB are presented by following the FPGA model. In section VIII, the paper is concluded with a point to the future.

\section{RELATED WORK}

The need for present-day control technology in the railroad industry is essential to speed up trains altogether and to accomplish high operation effectiveness and safety. The driving moment to the wheels is provided by traction motors of train and primary source of railway vehicle movement is originated from wheel-rail friction which is defined as adhesion force, the operational control of the train must be 
based on the nonlinear model of the wheel-rail interaction. The principle factor that makes this control issue troublesome is model nonlinearities and uncertainties where traction force and adhesion forces are not equal (adhesion force is less then traction force) therefore, good control algorithms are needed that will provide the effective utilization of adhesion force. The reduced adhesion force between rail and wheels results in increasing the slip which in result reduces the tractive effort, adhesion is complex, and changing over time and has various parameter conditions is a central factor that must be investigated in railroad analyzes. The coefficient of adhesion force on the various wheel-rail contact conditions relies upon parameters, such as contamination of the wheel-rail contact surface (oil, leaves, dampness, and unwanted grass), vehicle speed, and slip speed. The effect of contamination is random and it is practically difficult to show its dynamic the wheel moving along the track slip with the trigger of the track irregularities, which will cause a decline in the typical power between the rail and wheel in this way the adhesion will diminish.

Chou, et al. [1] have discussed the slip velocity which is defined as the difference between the angular velocity of the train wheel and train forward speed likewise effect on adhesion coefficient. It is conceivable to maximize coefficient by controlling the slip velocity for each wheel-rail contact condition, there exists a particular slip velocity at which the coefficient of adhesion force reached to its maximum value, using traction controller if the traction force between rail and wheel is maximized then the instability which is due to excessive wheel slip can be maintained or avoided. Numerous control algorithms have been created for train operation control. This kind of control plan concentrated on different parts of railroad vehicle dynamics, such as obstruction powers, non-linearity, traction, and braking constraints. Senini, et al. [2], has proposed that for high-speed train adhesion control, logic threshold control can be adopted as acceleration/ deceleration, creep-age rate, speed difference but this method acts after the occurrence of sliding and it needs a lot of experiments, therefore, it cannot result from the best use of adhesion and it is influenced by railroad conditions. Kondo [3] and Hata, et al. [4] have proposed that artificial intelligence can help to implement complex control systems in the railway industry; however, AI-based systems cannot be implemented in low model cars and bikes and are very expensive. Mei, et al. [5], have estimated wheel slip via Kalman filtering and anti-slip control in railway traction which investigates in wheelset dynamics modes originated by different wheel-rail contact condition and without requiring direct vehicle slip velocity it identifies slip from torsional resonant vibrations of wheelset axle due to relationship between torsional vibrations and wheel slip. Liao, et al. [6], utilizing an observer-based robust method has developed adhesion control strategy which is capable to attenuate wheel slip and use adhesion when the adhesion coefficient abruptly is getting lower, without necessitating the train speed size for evaluating authentic adhesion condition Based on a zero-order observer. Kadowaki, et al. [7], Kadowaki, et al. [8] set forward a new torque adjustment control algorithm activated by idling-sliding detection. Where the control impact is better, however, the use of adhesion remains should be improved. Wenli, et al. [9] Analyses the performance impact of full dimension observer to re-adhesion advancement control framework decidedly.

Ohishi, et al. [10] a torque feedback adhesion control is proposed based on zero-order observers. In the adhesion-slip stable region, the control is effective whereas in the unstable region torque feedback control will fail. Ohishi, et al. [11] proposed reduced-order observer adding extra torque command $\mathrm{c}(\mathrm{t})$ to torque regulator output in literature. Ohishi, et al. $[11\rceil$ Solve the adhesion slip unstable region failure problems of Ohishi, et al. [10]. Watanabe and Yamashita [12] have proposed an approach of slip detection besides using the velocity sensor by considering the torque contemporary differences of every traction motor fed with the aid of one inverter. By using this method, small wheel slips can be estimated, and the performance of this re-adhesion manipulate is as high as the manager with velocity sensors. Chih-Min and Hsu [13] Neural network applied to the antilock braking system has solved a lot of problems but the neural network needs a lot of experiments and its experiment needs a lot of actual data, therefore, it may fall in a local optimum. Yang, et al. [14], Huang, et al. [15], has proposed Sliding mode control (SMC) for anti-slip controller design and have reported that satisfactory control effects results are achieved. Hussain, et al. [16] have designed an indirect technique to identify adhesion that is available at the wheel-rail interface and tractive effort is adjusted accordingly in which bank of Kalman filters are used for adhesion identification and railway vehicle dynamics under different environmental conditions. Hussain, et al. [17] have developed multiple model estimation for the identification of adhesion limit and have shown variations in the dynamic behavior of railway wheelset with this Kalman filter have also been designed to select operation points for adhesion estimation but there are still come residuals from Kalman filters. Hussain, et al. [18] using the bank of Kalman filters based on linearized wheelset models of lateral and yaw dynamics have been calculated but the model does not have shown effective results for creep/slip curves. Mei, et al. [19] fault tolerance for railway wheelsets with a focus on actuator failures have been performed but it needs several control schemes.

In this paper, we present an efficient fuzzy logic-based based anti-slip control algorithm of commuter trains using FPGA that is designed, developed, and tested in MATLAB first and then implemented in FPGA using Xilinx ${ }^{\circledR}$ system generator.

\section{DYNAMIC EQUATIONS}

Wheel-set model of railway consists of two wheels connected through common axle rigidly so that a common angular velocity and distance is maintained between the wheels to rotate them smoothly. Each Wheel of the model has a cone shape with a flange inside which allows typically \pm 7 $10 \mathrm{~mm}$ lateral displacement before flange contact occurs as shown in Fig. 1. 


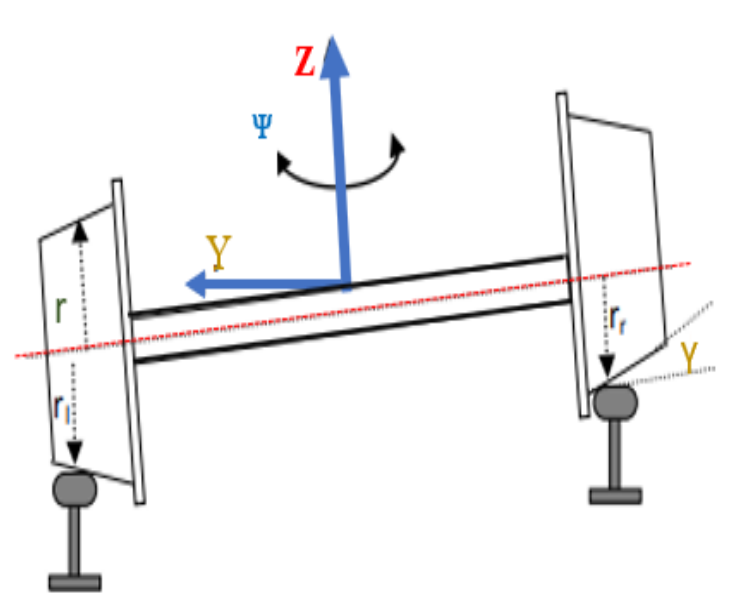

Fig. 1. Railway Wheelset Model.

Linear equations Kalker Model are used to determine wheel-rail creep contact forces which lead to threedimensional rolling contact. If $T_{t}$ is the torque generated by traction motor, the rotational dynamics of the wheel-set model are given below.

$$
\begin{aligned}
& I_{R} \omega_{R}=T_{t}-T_{k}-T_{R} \\
& I_{L} \omega_{L}=T_{k}-T_{L} \\
& \theta_{K} \omega_{R}-\omega_{L} \\
& T_{R}=r_{o} f_{11} \lambda_{X R} \\
& T_{L}=r_{o} f_{11} \lambda_{X L} \\
& \frac{\left(\omega_{R} \times r_{o}\right)-v}{v}=\lambda_{X R} \\
& \frac{\left(\omega_{L} \times r_{o}\right)-v}{v}=\lambda_{X L}
\end{aligned}
$$

Replacing $T_{R}$ and $T_{L}$ from equations 3 and 4 to equations 1 and 2 .

$$
\begin{aligned}
& I_{R} \omega_{R}=T_{t}-T_{k}-r_{o} f_{11} \lambda_{X R} \\
& I_{R} \omega_{R}=T_{t}-T_{k}-r_{o} f_{11} \frac{\left(\omega_{R} \times r_{o}\right)-v}{v} \\
& \omega_{R}=T_{t}-T_{k}-r_{o} f_{11} \frac{\left(\omega_{R} \times r_{o}\right)-v}{v} \\
& \omega_{R}=\frac{T_{t}}{I_{R}}-\frac{T_{k}}{I_{R}}-\frac{r_{o}^{2} f_{11} \omega_{R}}{I_{R}}-\frac{r_{o} f_{11} v}{I_{R}} \\
& I_{L} \omega_{L}=T_{k}-T_{L} \\
& I_{L} \omega_{L}=T_{t}-T_{k}-r_{o} f_{11} \lambda_{X L} \\
& I_{L} \omega_{L}=T_{t}-T_{k}-r_{o} f_{11} \frac{\left(\omega_{L} \times r_{o}\right)-v}{v} \\
& \omega_{L}=\frac{T_{t}}{I_{L}}-\frac{T_{k}}{I_{L}}-\frac{r_{o}^{2} f_{11} \omega_{L}}{I_{L}}-\frac{r_{o} f_{11} v}{I_{L}} \\
& \theta_{K} \omega_{R}-\omega_{L}
\end{aligned}
$$

$$
\begin{aligned}
& \theta_{s}=\left(\frac{T_{t}}{I_{R}}-\frac{T_{k}}{I_{R}}-\frac{T_{R}}{I_{R}}\right)-\left(\frac{T_{k}}{I_{L}}-\frac{T_{L}}{I_{L}}\right) \\
& \left|\begin{array}{c}
\omega_{R} \\
\omega_{L} \\
\theta_{S}
\end{array}\right|=\left|\begin{array}{ccc}
-\frac{r_{o}{ }^{2} f_{11}}{I_{R}} & 0 & \frac{k}{I_{R}} \\
0-\frac{r_{0}^{2} f_{11}}{I_{R}} & \frac{k}{I_{L}} \\
1-1 & -1
\end{array}\right| \begin{array}{c}
\omega_{R} \\
\omega_{L} \\
\theta_{S}
\end{array}|+| \begin{array}{c}
\frac{1}{I_{R}} \\
0 \\
0
\end{array} \mid
\end{aligned}
$$

Where $I_{R}$ is the moment of inertia of right wheel, $I_{l}$ is the moment of inertia of left wheel, the moment of inertia which is also called as rotational inertia, it is specified w.r.t to the chosen axis of rotation of wheels, $\omega_{R}$ is the angular velocity of the right wheel, $\omega_{l}$ is the angular velocity of the left wheel which is defined as is the rate of change of angle, $T_{t}$ is the torque, $\theta_{k}$ is the torsional angle, $r_{o}$ is the radius of both the wheels, $f_{11}$ are linearized kalker coefficient which is used in several wheel-rail contact theories and determine spin moment and tangential forces defining the relationship between lateral creepage, longitudinal and creep force, $\lambda_{X R}$ and $\lambda_{X L}$ represent slip of right and left wheel respectively.

The dynamics of wheelset represented by equation 5 indicates that wheel-set depend on adhesion and speed of the vehicle at the wheel-rail interface if all parameters other than speed and adhesion are constant which depend upon manufacturer and defined during the manufactured process, therefore the only parameters that affect the system stability are speed and friction level on the tracks whereas all other parameters given in the equation 5 are defined at the time of manufacturing process.

\section{WHEELSET MODEL}

A Wheelset consists of the Left wheel and Right wheel, Torque is input to a wheelset that will produce subsequent motion to wheel and the initial velocity is set as $20 \mathrm{~m} / \mathrm{s}$. The simulation platform is developed in MATLAB/SIMULINK and converted into a system generator for FPGA synthesize as shown in Fig. 2.

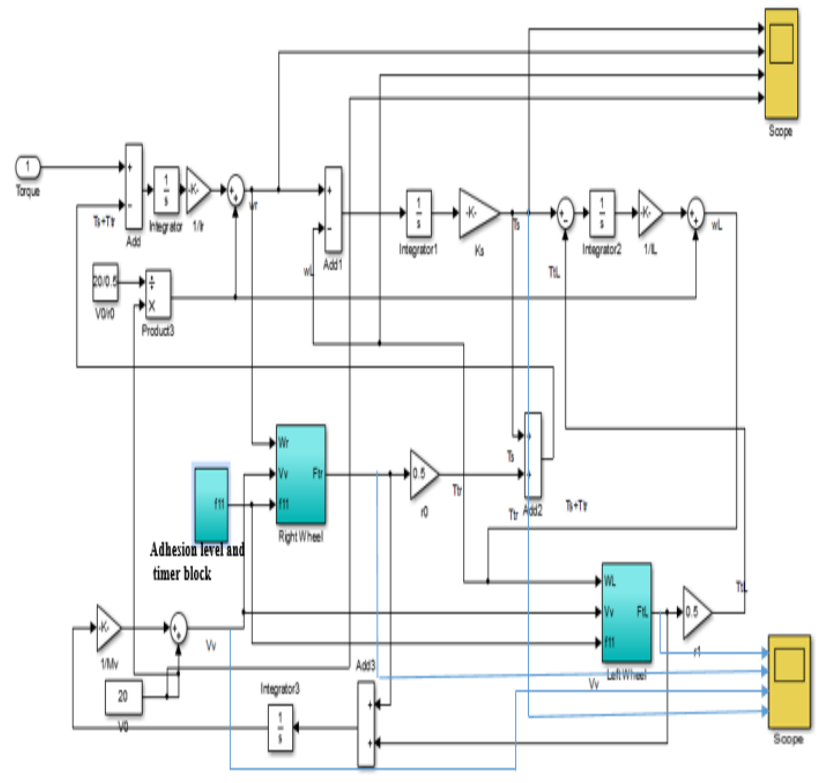

Fig. 2. Matlab based Vehicle-Set Model. 
In the adhesion level and timer block of Fig. 2 adhesion level and a timer of $5 \mathrm{sec}$ are set representing that during the first $5 \mathrm{sec}$ of simulation adhesion level will be high and after 5 sec of stimulation, adhesion will be low so to analyze the behavior of the model.

During the low adhesion level speed of wheels increase abruptly whereas the speed of the vehicle does not increase in proportion with the speed of wheels causing wheels to slip. If this is not controlled can cause damage to rolling wheels and track which also wastes tractive effort reducing the efficiency.

In Fig. 3, 4, 5 and 6 the behavior of applied torque, vehicle speed, left and right wheel speed are shown. During the first 5 sec adhesion was kept high. At that time applied torque was completely converted into accelerating the vehicle and speed of train varies in equal proposition with right and left wheel speed. After 5 secs adhesion was switched from high to low.

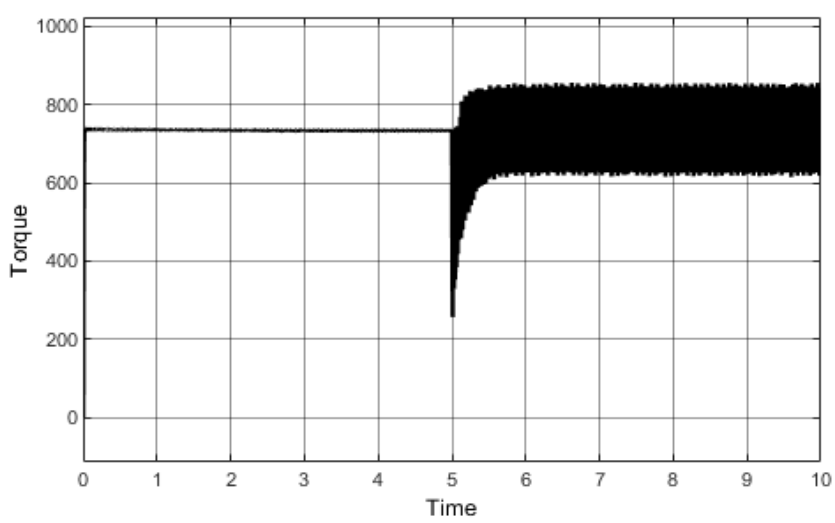

Fig. 3. Behavior of Torque without Controller.

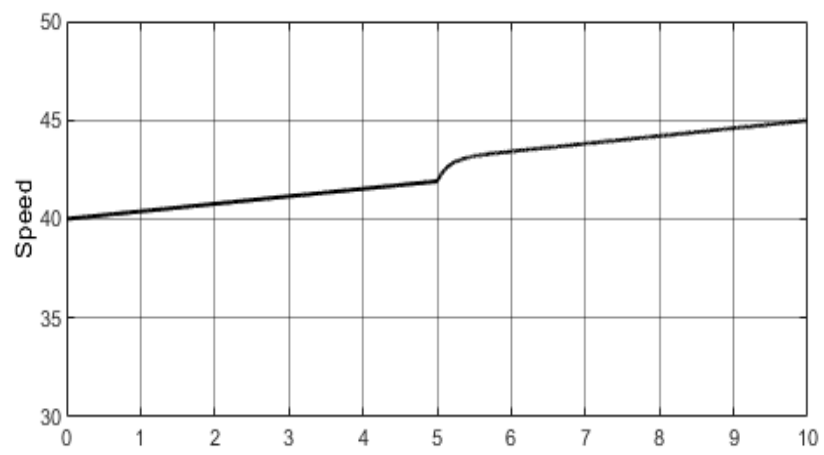

Fig. 4. Right Wheel Speed without Controller.

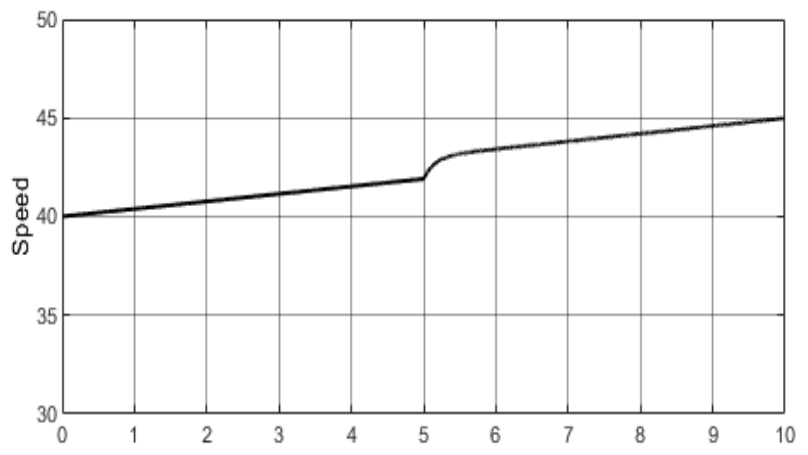

Fig. 5. Left Wheel Speed without Controller.

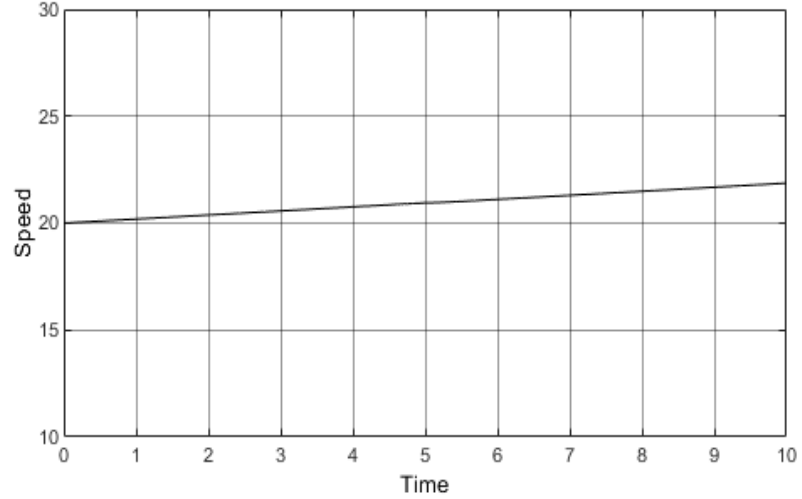

Fig. 6. Vehicle Speed without Controller.

In that time, applied torque produced irregulating vibration and there is a difference of vehicle speed in right and left wheel speed which represents that wheels are slipping.

Table I shows the difference in speed of train and wheels without any controller at initial velocity of 20 which is 23 indicating that train is slipping due to difference in vehicle and wheel speed.

TABLE I. Vehicle-WheEl SPEed Without CONTROLLER

\begin{tabular}{|l|l|}
\hline Vehicle Speed & Wheel Speed \\
\hline 20 & 43 \\
\hline
\end{tabular}

\section{PID CONTROLLER}

The simulation platform is built in MATLAB/SIMULINK system generator to evaluate the performance of the proposed anti-slip controller. PID controller is designed to control wheels from slipping, several experiments were carried out to analyze the behavior of wheelset model at different $\mathrm{Kp}$, Kii, and $\mathrm{Kd}$ values and suitable values for this model are 200, 50, 0.25 respectively. In this paper, a PID based model is designed to compare the effect of fuzzy and PID controller. The actual design intends for this kind of controller is to maintain the desired slip. The input to the controller is error signal and out is represented as equation 6 .

Output $=K_{p e}(t)+K_{i} \int e(t) d t+K_{D} \frac{d}{d t} e(t)$

Where $K_{p}, K_{i}, K_{d}$ are proportional gain, integral coefficient, derivative coefficient respectively.

Fig. 7 represents a PID based wheelset model, the value of $\mathrm{Kp}, \mathrm{Ki}, \mathrm{Kd}$ was set by hit and trial method. The 's' block in the model is adhesion level block during the first 5 secs adhesion level was kept low and after 5 secs adhesion level was shifted to high to check the behavior of left and right wheel of the train.

In Fig. 8 behavior of applied torque is shown which indicates that after 5 secs applied torque is converted into irrigating vibrations which are not good for the performance of the train and comfort of passengers.

In Fig. 9, 10 and 11 speed of the left wheel, right wheel and speed of the train is shown respectively with PID controller indicating that the speed of train has not increased 
as the speed of left and right wheel has increased which means that the train is slipping because the speed of vehicle differs the speed of wheels.

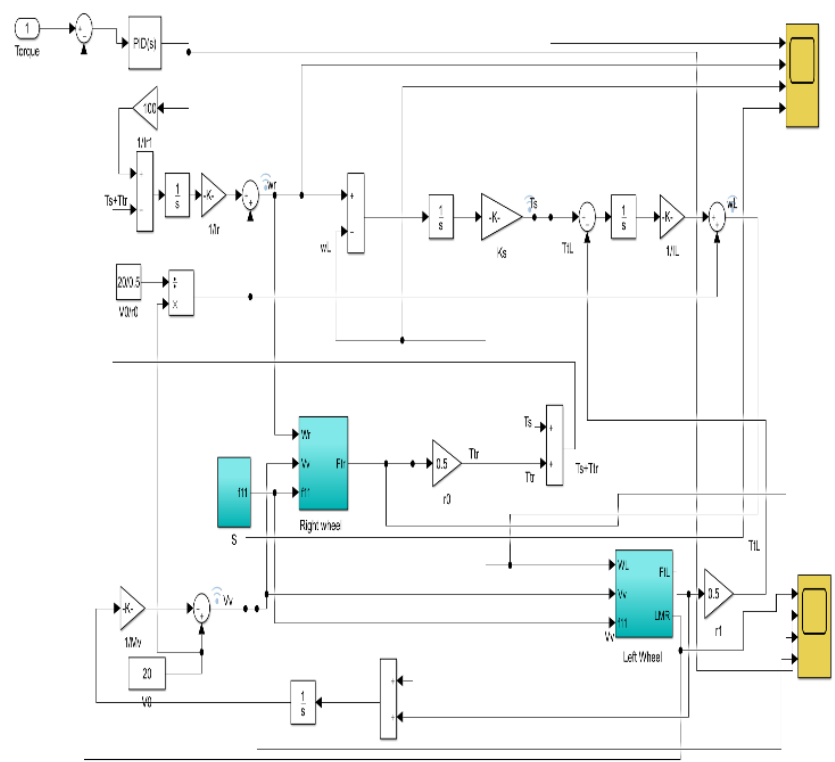

Fig. 7. PID based Wheelset Model.

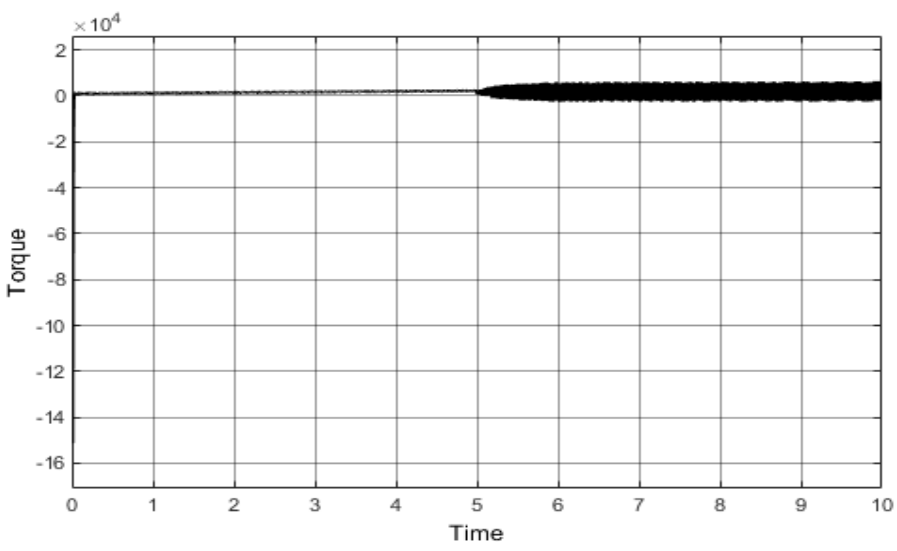

Fig. 8. Behavior of Torque with PID Controller.

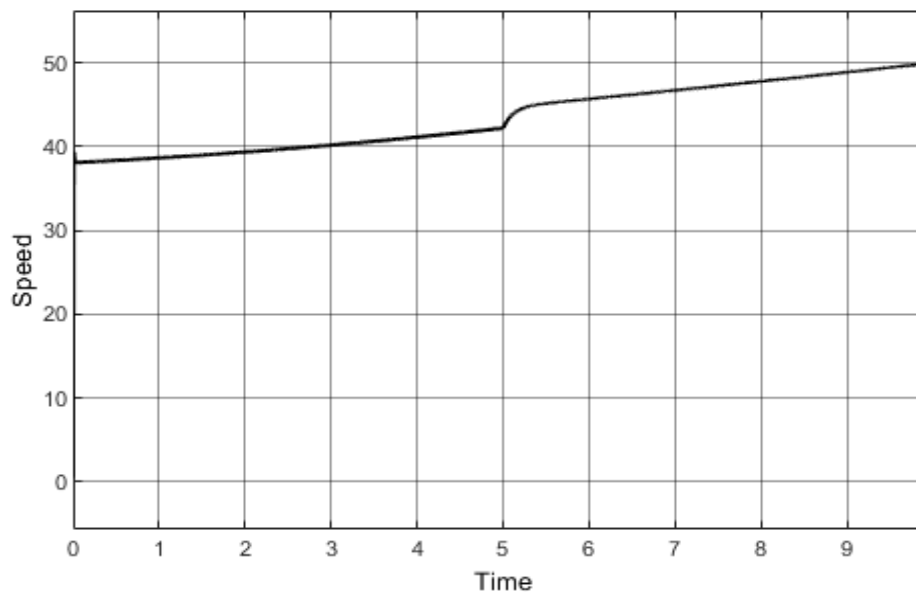

Fig. 9. Speed of Left Wheel with PID Controller.

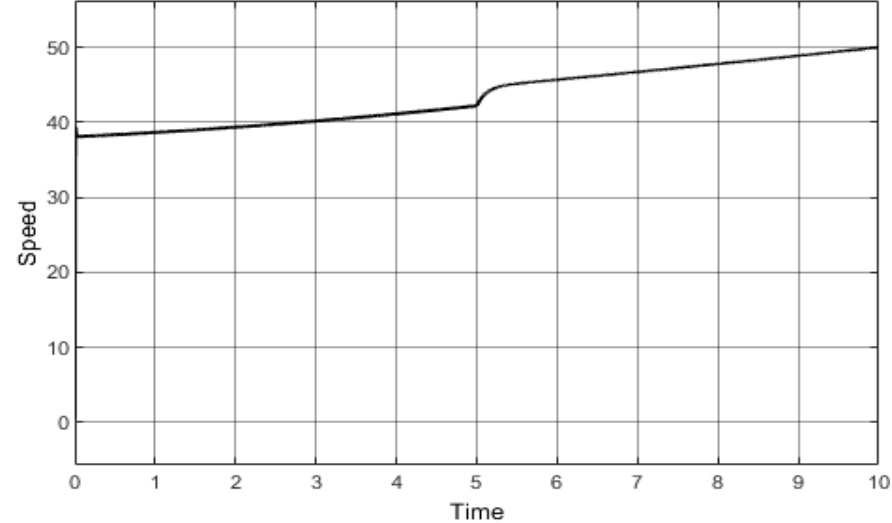

Fig. 10. Speed of Right Wheel with PID Controller.

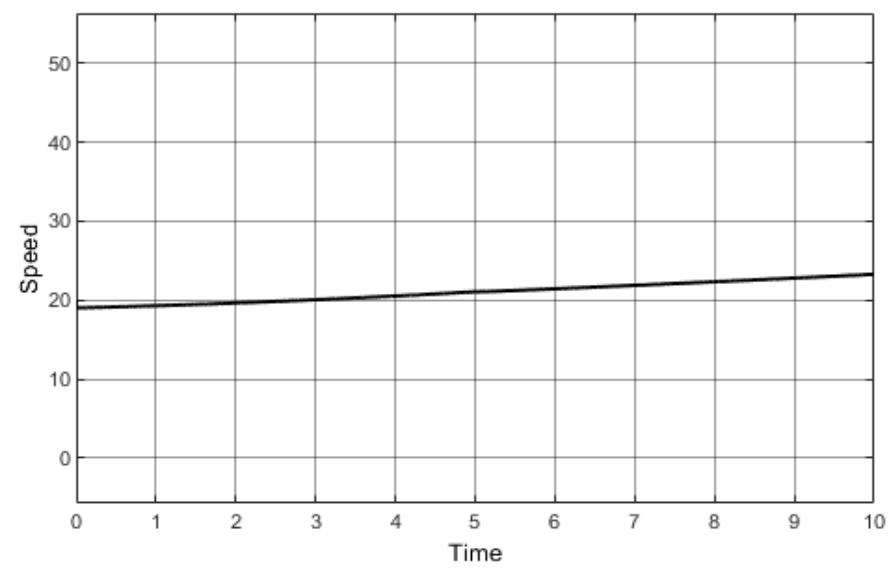

Fig. 11. Speed of Vehicle with PID Controller.

Table II shows the difference in speed of train and wheels with PID controller at initial velocity of 20 which is 13.7 indicating that slip has been controlled using PID controller.

TABLE II. VEHICLE-WheEl SPEED WITH PID CONTROLLER

\begin{tabular}{|l|l|}
\hline Vehicle Speed & Wheel Speed \\
\hline 20 & 33.7 \\
\hline
\end{tabular}

\section{PROPOSED FuZZY-LOGIC CONTROLLER}

Fuzzy based wheel-set model is designed according to the fuzzy control principle. The fuzzy controller has two inputs which are actual slip and threshold slip.

The fuzzy controller generates output according to the current input values and fuzzy rules that are set. Mamdani and Sugeno method are used to perform the fuzzy calculation and defuzzied identification. The fuzzy controller-based model is described as in Fig. 12.

Table III represents $7 \times 7$ error rate for fuzzy membership function.In $7 \times 7$ rule, there is 7 membership function were namely as:

Slip error: Slip change rate:

$\mathrm{Z}=$ zero $\mathrm{NL}=$ negative large

$\mathrm{VS}=$ very small $\mathrm{NS}=$ negative small 
$\mathrm{TO}=$ too small $\mathrm{Z}=$ zero

$\mathrm{STO}=$ small than optimum TS $=$ too small

$\mathrm{O}=$ optimum $\mathrm{O}=$ optimum

$\mathrm{TL}=$ too large $\mathrm{TL}=$ too large

$\mathrm{VL}=$ very large $\mathrm{VL}=$ very large

Table IV shows $7 \times 7$ slip error and the parameter range between membership function has been adjusted and the difference between each parameter point is 0.37 and the parameter range for the $1^{\text {st }}$ parameter to $3^{\text {rd }}$ is from $0-2.94$.

Table V shows $7 \times 7$ slip error change and the parameter range between membership function has been adjusted and the difference between each parameter point is -1.03 and the parameter range for the $1^{\text {st }}$ parameter to $3^{\text {rd }}$ is from -1.4 to 1.56 .

Fuzzy based wheel model is represented by Fig. 13 to control the slip of train.

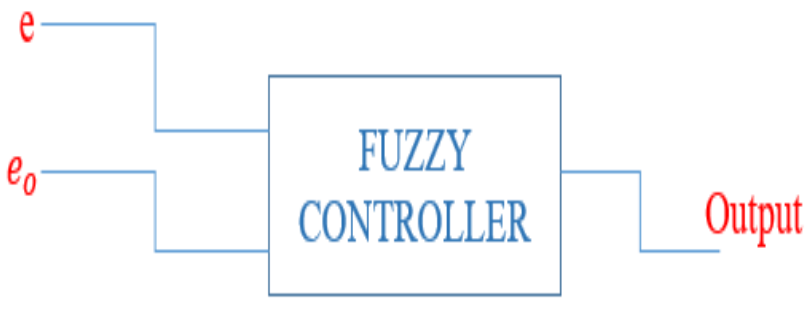

Fig. 12. FLC Structure.

TABLE III. 7X7 ERROR RATE

\begin{tabular}{|l|l|l|l|l|l|l|l|}
\hline $\begin{array}{l}\text { Slip } \\
\text { error/change } \\
\text { of error }\end{array}$ & NL & NS & Z & TS & O & TL & VL \\
\hline Z & PL & PL & PL & PL & PM & PS & \\
\hline VS & PL & PL & PM & PM & PS & PS & NS \\
\hline TS & PL & PM & PM & PS & PS & NS & NS \\
\hline STO & PM & PS & NM & NL & NL & NL & NM \\
\hline O & NS & NS & NM & NM & NL & NL & \\
\hline TL & NS & NS & Z & NM & NL & NL & \\
\hline VL & NS & NS & NS & & & & \\
\hline
\end{tabular}

TABLE IV. $\quad 7 \times 7$ SLIP ERROR

\begin{tabular}{|c|c|c|c|}
\hline \multirow{2}{*}{ Name } & \multicolumn{3}{|c|}{ Parameters } \\
\hline & $1^{\mathrm{ST}}$ & $2^{\text {nd }}$ & $3^{\text {rd }}$ \\
\hline Z & 0 & 0.37 & 0.74 \\
\hline VS & 0.37 & 1.7 & 1.11 \\
\hline TS & 0.74 & 1.11 & 1.48 \\
\hline STO & 1.11 & 1.48 & 1.85 \\
\hline $\mathrm{O}$ & 1.48 & 1.85 & 2.2 \\
\hline TL & 1.85 & 2.2 & 2.57 \\
\hline VL & 2.2 & 2.57 & 2.94 \\
\hline
\end{tabular}

TABLE V. $\quad 7$ X7 SLIP ERROR CHANGE

\begin{tabular}{|l|l|l|l|}
\hline \multirow{2}{*}{ Name } & \multicolumn{2}{|l|}{ Parameters } & $2^{\text {nd }}$ \\
\cline { 2 - 4 } & $1^{\text {ST }}$ & -1.03 & $3^{\text {rd }}$ \\
\hline Z & -1.4 & -0.66 & -0.66 \\
\hline VS & -1.03 & -0.29 & -0.29 \\
\hline TS & -0.66 & 0.08 & 0.08 \\
\hline STO & -0.29 & 0.45 & 0.45 \\
\hline O & 0.08 & 0.82 & 0.82 \\
\hline TL & 0.45 & 1.19 & 1.19 \\
\hline VL & 0.82 & & 1.56 \\
\hline
\end{tabular}

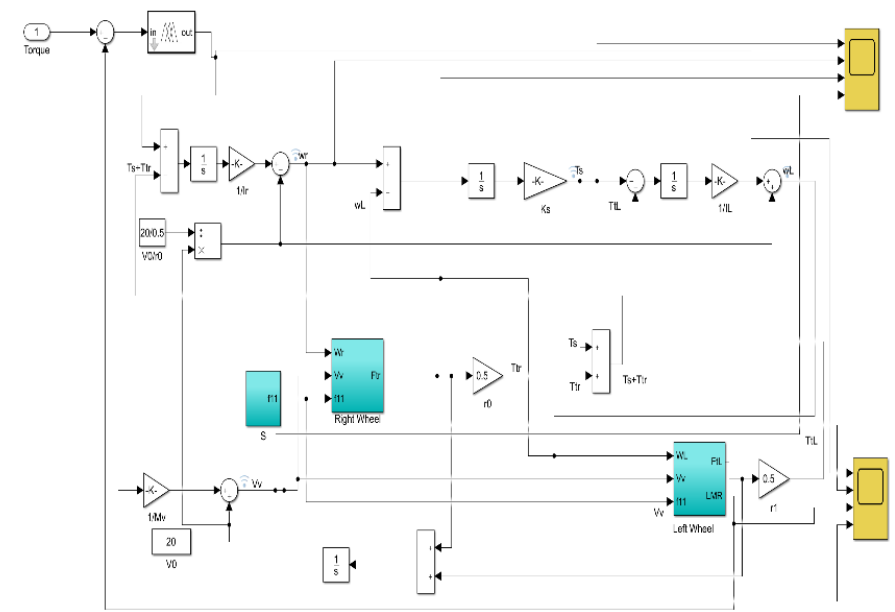

Fig. 13. Fuzzy based Wheelset Model.

In Fig. 14, 15, 16, and 17, is shown the behavior of the model with the fuzzy controller, indicating that with the fuzzy controller wheel slip has improved as with the increasing speed of the vehicle, wheel speed is increasing in almost equal proportion even after the adhesion level is switched from high to low after $5 \mathrm{sec}$ of simulation. The behavior of applied torque is also improved during the time of low adhesion.

Table VI shows difference of speed between train and wheels using fuzzy logic controller which is 0.03 which clearly indicates that slip has been controlled through fuzzy logic controller.

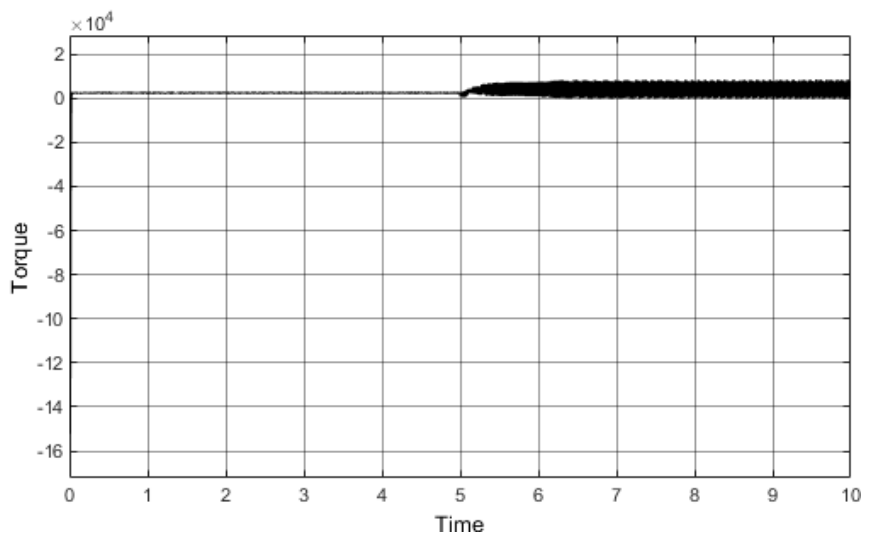

Fig. 14. Behavior of Torque with Fuzzy Controller. 


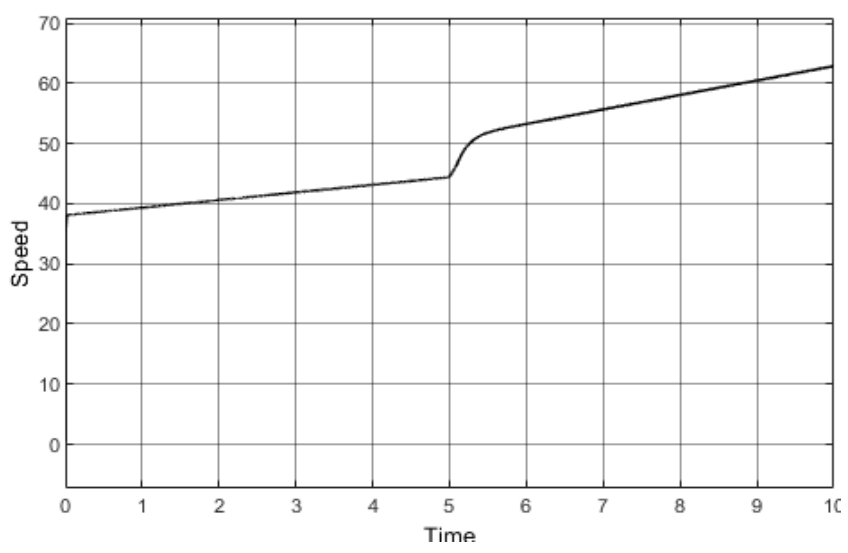

Fig. 15. Speed of Left Wheel with Fuzzy Controller.

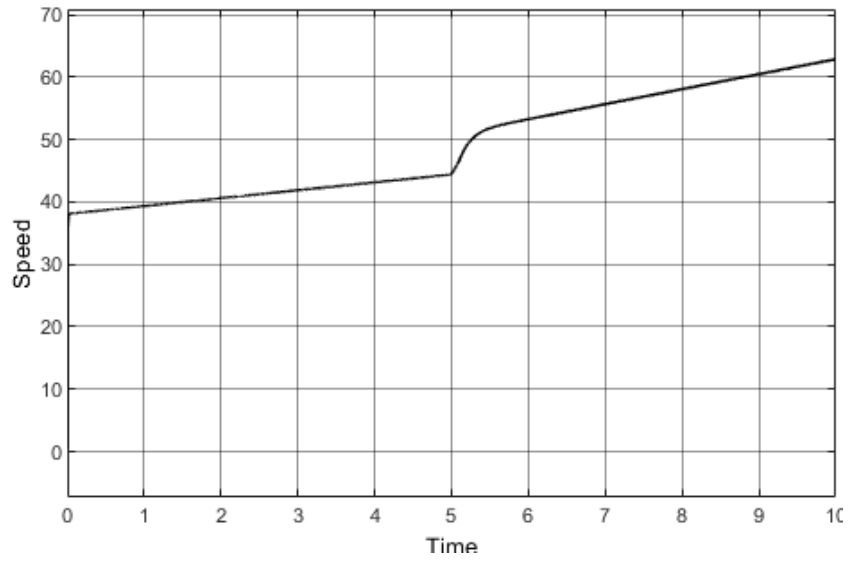

Fig. 16. Speed of Right Wheel with Fuzzy Controller.

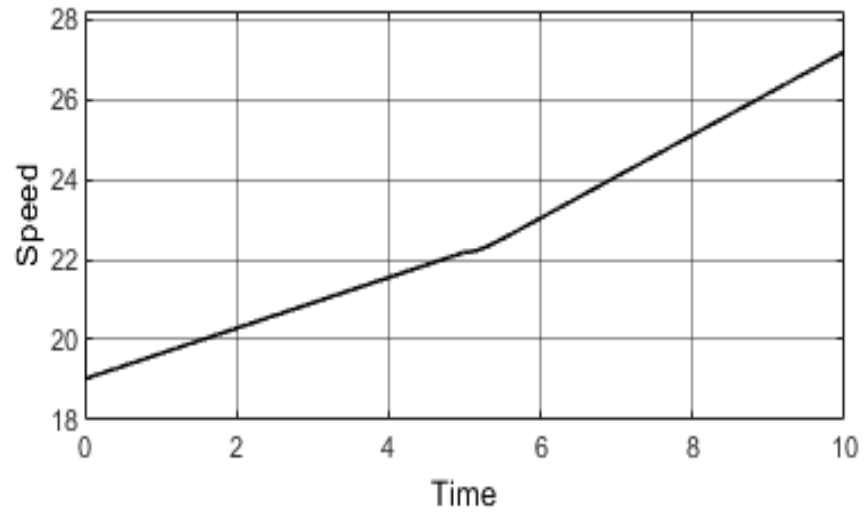

Fig. 17. Speed of Vehicle with Fuzzy Controller.

TABLE VI. VeHICLE-WHEel SPEED With FuZZY CONTROLLER

\begin{tabular}{|l|l|}
\hline Vehicle Speed & Wheel Speed \\
\hline 20 & 20.03 \\
\hline
\end{tabular}

Table VII shows Vehicle- Wheel behavior at different speed also gives comparison without a controller and with PID and fuzzy controller.
TABLE VII. COMPARING OF VeHICLE-WHEELS AT DIFFERENT SPEEDS

\begin{tabular}{|l|l|l|l|}
\hline Vehicle Speed & $\begin{array}{l}\text { Right-left } \\
\text { Wheel speed } \\
\text { without } \\
\text { controller }\end{array}$ & $\begin{array}{l}\text { Right-left } \\
\text { Wheel speed } \\
\text { with PID } \\
\text { Controller }\end{array}$ & $\begin{array}{l}\text { Right- left Wheel } \\
\text { speed with fuzzy } \\
\text { Controller }\end{array}$ \\
\hline 20 & 43 & 33.7 & 20.03 \\
\hline 40 & 51 & 47.1 & 41.03 \\
\hline 60 & 83 & 70.03 & 60.03 \\
\hline 80 & 126 & 91.7 & 80.03 \\
\hline 100 & 208 & 110.2 & 100.03 \\
\hline
\end{tabular}

\section{VII.FPGA BASED MODEL}

Simulation results show that the fuzzy-based model has better performance efficiency therefore it is further converted into a fuzzy-based FPGA model as shown in Fig. 18 for hardware specification. This Spartan 6 board is selected which represents that when fuzzy-based -anti-slip control model will be converted into practical use than it will utilize 118 number of slices, 15 number of flip flop, 14 BRAMS, 18 LUTS, 46 IOBS, 18 MULTS/DSP 48S. Table VIII shows the hardware specification of the FPGA- Fuzzy based model.

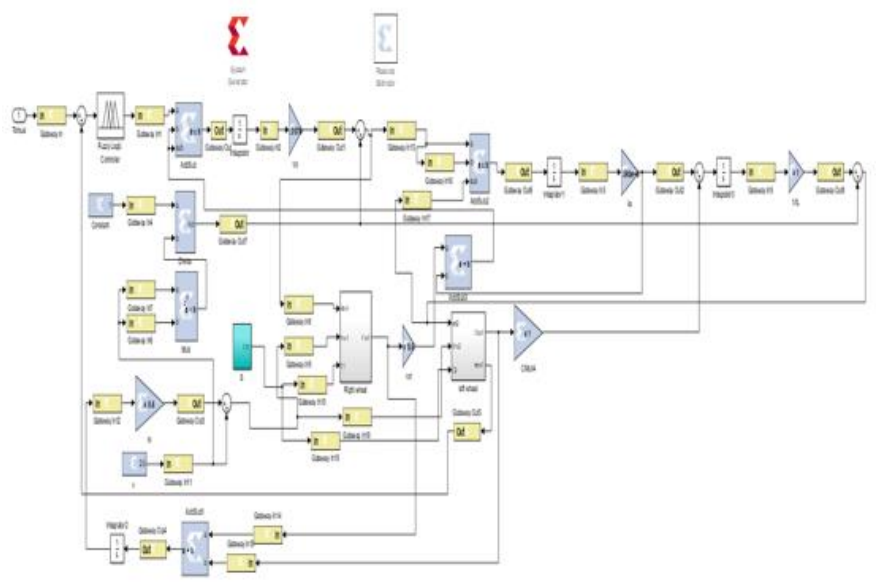

Fig. 18. FPGA based Fuzzy Model.

TABLE VIII. HARDWARE SPECIFICATION

\begin{tabular}{|l|l|l|}
\hline \multicolumn{2}{|l|}{ Spartan 6 (6slx I6csg 324-3) } & AVAILABLE \\
\hline RESOURCES & USED & 9112 \\
\hline Number of Slices & 118 & 18224 \\
\hline Number of FFS & 15 & 612 \\
\hline BRAMS & 14 & 32 \\
\hline LUTS & 18 & 64 \\
\hline IOBS & 46 & 2278 \\
\hline MULT/DSP48s & 18 & \\
\hline
\end{tabular}




\section{CONCLUSION}

In this paper, we have focused on a critical issue that is faced by commuter trains at high speed. The system was modeled using the PID controller and Fuzzy logic controller both the models have a controlled slip of train but the fuzzybased wheelset model has given better results to control the slip of train during low adhesion level, therefore, the fuzzybased model was converted to FPGA for area and power performance.

\section{ACKNOWLEDGMENT}

We acknowledge the support of national lab 'Haptics, Human, Robotics and Condition Monitoring System established at Mehran University of Engineering and Technology Jamshoro under the consortium model of National Center of Robotics and Automation, HEC Pakistan.

\section{REFERENCES}

[1] M. Chou, X. Xia, and C. Kayser, "Modelling and model validation of heavy-haul trains equipped with electronically controlled pneumatic brake systems," Control Engineering Practice, vol. 15, no. 4, pp. 501509, 2007/04/01/ 2007, doi: https://doi.org/10.1016/j.conengprac.2006. 09.006 .

[2] S. Senini, F. Flinders, and W. Oghanna, "Dynamic simulation of wheelrail interaction for locomotive traction studies," in Proceedings of the 1993 IEEE/ASME Joint Railroad Conference, 6-8 April 1993 1993, pp. 27-34, doi: 10.1109/RRCON.1993.292967.

[3] K. Kondo, "Anti-slip control technologies for the railway vehicle traction," in 2012 IEEE Vehicle Power and Propulsion Conference, 9-12 Oct. 2012 2012, pp. 1306-1311, doi: 10.1109/VPPC.2012.6422493.

[4] T. Hata et al., "Anti-slip re-adhesion control based on speed sensor-less vector control and disturbance observer for electric multiple units, series 205-5000 of East Japan Railway Company," in IEEE International Conference on Industrial Technology, 2003, 10-12 Dec. 2003 2003, vol. 2, pp. 772-777 Vol.2, doi: 10.1109/ICIT.2003.1290755.

[5] T. X. Mei, J. H. Yu, and D. A. Wilson, "A Mechatronic Approach for Anti-slip Control in Railway Traction," IFAC Proceedings Volumes, vol. 41, no. 2, pp. 8275-8280, 2008/01/01/ 2008, doi: https://doi.org/ $10.3182 / 20080706-5-K R-1001.01399$.

[6] W. Liao, H. Chen, W. Cai, and Y. Song, "A novel active adhesion control design for high speed trains without vehicle speed measurement," in Proceedings of the 33rd Chinese Control Conference, 28-30 July 2014 2014, pp. 221-226, doi: 10.1109/ChiCC.2014.6896625.

[7] S. Kadowaki, K. Ohishi, I. Miyashita, and S. Yasukawa, "Anti-Slip Readhesion Control of Electric Motor Coach (2M1C) Based on Disturbance Observer and Speed Sensor-Less Vector Control," IEEJ Transactions on Industry Applications, vol. 121, pp. 1192-1198, 01/01
2001, doi: 10.1541/ieejias.121.1192.

[8] S. Kadowaki et al., "Antislip Readhesion Control Based on SpeedSensorless Vector Control and Disturbance Observer for Electric Commuter Train-Series 205-5000 of the East Japan Railway Company," IEEE Transactions on Industrial Electronics, vol. 54, no. 4, pp. 2001-2008, 2007, doi: 10.1109/TIE.2007.895135.

[9] L. Wenli, Z. Leiting, and D. Kan, "Performance Analysis of Re-adhesion Optimization Control Based On Full-dimension State Observer," Procedia Engineering, vol. 23, pp. 531-536, 2011/01/01/ 2011, doi: https://doi.org/10.1016/j.proeng.2011.11.2543.

[10] K. Ohishi, Y. Ogawa, I. Miyashita, and S. Yasukawa, "Adhesion control of electric motor coach based on force control using disturbance observer," in 6th International Workshop on Advanced Motion Control. Proceedings (Cat. No.00TH8494), 30 March-1 April 2000 2000, pp. 323-328, doi: 10.1109/AMC.2000.862884.

[11] K. Ohishi, K. Nakano, I. Miyashita, and S. Yasukawa, "Anti-slip control of electric motor coach based on disturbance observer," in AMC'98 Coimbra. 1998 5th International Workshop on Advanced Motion Control. Proceedings (Cat. No.98TH8354), 29 June-1 July 1998 1998, pp. 580-585, doi: 10.1109/AMC.1998.743601.

[12] T. Watanabe and M. Yamashita, "A novel anti-slip control without speed sensor for electric railway vehicles," in IECON'01. 27th Annual Conference of the IEEE Industrial Electronics Society (Cat. No.37243), 29 Nov.-2 Dec. 2001 2001, vol. 2, pp. 1382-1387 vol.2, doi: 10.1109/IECON.2001.975983.

[13] L. Chih-Min and C. Hsu, "Neural-network hybrid control for antilock braking systems," IEEE Transactions on Neural Networks, vol. 14, no. 2, pp. 351-359, 2003, doi: 10.1109/TNN.2002.806950.

[14] Y. Yang, Z. Xu, W. Liu, H. Li, R. Zhang, and Z. Huang, "Optimal Operation of High-Speed Trains Using Hybrid Model Predictive Control," Journal of Advanced Transportation, vol. 2018, pp. 1-16, 05/15 2018, doi: 10.1155/2018/7308058.

[15] Z. Huang, Z. Xu, B. Chen, R. Zhang, Y. Chen, and Q. Peng, "Sliding mode control for urban railway anti-slip system based on optimal slip ratio estimation with forgetting factor recursive least-squares," in 2017 36th Chinese Control Conference (CCC), 26-28 July 2017 2017, pp. 9502-9507, doi: 10.23919/ChiCC.2017.8028873.

[16] I. Hussain, I. Halepoto, W. Kumar, and K. Kazi. Anti-Slip Traction Control of Railway Vehicle Based on Estimated Wheel-Rail Contact Condition.

[17] I. Hussain, T. X. Mei, and R. T. Ritchings, "Estimation of wheel-rail contact conditions and adhesion using the multiple model approach," Vehicle System Dynamics, vol. 51, no. 1, pp. 32-53, 2013/01/01 2013, doi: 10.1080/00423114.2012.708759.

[18] I. Hussain, A. Khoso, and M. Abro, Fuzzy Logic Based Adaptive Traction Control System. 2017.

[19] T. Mei, J. Yu, and D. Wilson, Proc. Inst. Mech. Eng.F:J.Rail Rapid Transit, Vol.233,no,null,p.295,2009 